\title{
Uptake of intermittent preventive treatment with sulphadoxine-pyrimethamine for malaria during pregnancy and pregnancy outcomes: a cross-sectional study in Geita district, North-Western Tanzania
}

\author{
Filbert J Mpogoro ${ }^{1 *}$, Dismas Matovelo ${ }^{2}$, Aliyah Dosani $^{3}$, Sospatro Ngallaba ${ }^{1}$, Moshi Mugono $^{1}$ \\ and Humphrey D Mazigo ${ }^{4}$
}

\begin{abstract}
Background: Malaria infection during pregnancy is associated with adverse outcomes in sub-Saharan Africa (SSA). For this reason, the World Health Organization currently recommends intermittent preventive treatment of malaria in pregnancy (IPTp) with sulphadoxine-pyrimethamine (SP) at each scheduled antenatal care (ANC) visit. In Tanzania, the revised IPTp policy was adopted in 2013 but the level of uptake and its association with pregnancy outcomes remains unknown.
\end{abstract}

Methods: A cross-sectional study was conducted among singleton pregnant women who delivered in two selected health facilities of Geita district, northwestern Tanzania. Self-reported uptake of SP was verified using the ANC card and was recorded. Placental and peripheral blood was collected for diagnosis of malaria by microscopy and rapid diagnostic tests (RDTs). Gestational age was estimated based on last menstrual period or Ballard score. Infant birth weights were recorded within 24 hours of delivery.

Results: Of 431 participants, 167 (38.75\%), 134 (31.09\%), 104 (24.23\%), and 26 (6.03\%) reported taking none, one, two, and $\geq$ three doses of SP during pregnancy, respectively. The uptake of $\geq$ three doses of IPTp-SP among delivering women at Geita hospital and Katoro health centre was $9.06 \%$ and $1.2 \%$, respectively. The overall prevalence of malaria in pregnancy by RDT, peripheral and placental smears was 19.5\%, 29.7\% and 37.6\% respectively. The prevalence of placental parasitaemia was higher for women who delivered at Katoro Health Centre (41.57\%) than those who delivered at Geita hospital (35.09\%). The uptake of $\geq$ three doses of SP was associated with reduced odds of having placental malaria (adjusted odds ratio $(A O R)=0.31, p=0.039)$ compared to $<$ three doses. Women with placental parasitaemia were five times more likely to have delivered pre-term ( $A O R=4.67, p=0.002)$ and had lower mean birth weight infants than their uninfected counterparts (mean difference $=82 \mathrm{~g}, p=0.039$ ).

Conclusions: The uptake of $\geq$ three doses of IPTp-SP is low in the present study area. Placental parasitaemia is prevalent and is associated with adverse birth outcomes. Receipt of $\geq$ three doses of IPTp-SP reduced the odds of placental parasitaemia. Thus, increased efforts towards scale-up and continuous evaluation of IPTp-SP efficacy is recommended.

Keywords: Pregnancy, Intermittent preventive treatment, Sulphadoxine-pyrimethamine placental malaria, Pre-term delivery, Low birth weight, Tanzania

\footnotetext{
* Correspondence: filbertmp@yahoo.com

${ }^{1}$ School of Public Health, Catholic University of Health and Allied Sciences-

Bugando, PO Box 1464, Mwanza, Tanzania

Full list of author information is available at the end of the article
} 


\section{Background}

Of the 125 million pregnant women who are at risk of Plasmodium falciparum infection each year, 30 million are from SSA [1]. Plasmodium falciparum malaria infection during pregnancy presents significant risks for the pregnant woman, the developing foetus and the newborn infant. The negative consequences associated with malaria in pregnancy include: severe malaria, severe anaemia, pre-term delivery, maternal death, and placental malaria [2-4]. Placental malaria is linked to intrauterine growth restriction, stillbirth, and delivery of low birth weight (LBW) infants $[5,6]$. Pre-term delivery and LBW are the risk factors for neonatal and infant deaths [7]. In Africa where malaria is endemic, malaria-causing LBW kills between 62,000 and 363,000 new-borns every year [8,9]. In Tanzania, 93\% of the population is at risk of malaria infection. Plasmodium falciparum malaria is responsible for up to 125,000 deaths in Tanzania, of which, 70,000-80,000 deaths occur in children who are under five years old [10]. The disease accounts for at least one fifth of all maternal deaths in Tanzania [11]. To prevent the effects of $P$. falciparum malaria during pregnancy, the World Health Organization (WHO) currently recommends intermittent preventive treatment of malaria in pregnancy (IPTp) using sulphadoxinepyrimethamine (SP) at each scheduled antenatal care (ANC) visit after the first trimester [12]. In SSA, the effectiveness of IPTp-SP in preventing malaria-related adverse pregnancy outcomes is well established [13-15]. Despite the widespread adoption of IPTp in malariaendemic countries in Africa, the coverage of recommended doses of IPTp-SP remains elusive [16]. In 2012, the median coverage of at least one, two and three doses of SP during pregnancy in SSA was 64\% (range 25-85\%), $38 \%$ (range 10-64\%), and 23\% (range 2-44\%), respectively [17]. In Tanzania, the coverage of at least one and two doses as per Tanzania HIV/AIDS Malaria Indictor Survey $2011 / 12$ was $60 \%$ and $32 \%$, respectively [18]. In addition, the widespread SP resistance caused by $P$. falciparum dihydrofolate reductase/dihydropteroate synthase (pfdhfr) pfdhps) quintuple or sextuple mutations $[19,20]$ is likely to affect the efficacy of SP in East Africa, including Tanzania. However, a recent systematic review and meta-analysis showed beneficial effects of three or more doses of SP during pregnancy in prevention of malaria-related adverse outcomes, even in areas with moderate to high SP resistance [21]. The new IPTp regimen has recently been implemented in Tanzania; thus the level of uptake and its association with pregnancy outcomes remains unknown in various regions of the country. The purpose of the present study was to determine the uptake of SP among pregnant women based on the revised recommendations, and to evaluate its association with adverse pregnancy outcomes, including placental malaria, pre-term delivery and LBW.

\section{Methods}

Study sites, design, participants and selection

This analytical cross-sectional study was conducted from May to June 2014 in delivery units at Geita district hospital and Katoro health centre, north-western Tanzania. Geita hospital is located within the capital city of Geita region (urban) while Katoro rural health centre is located 45 kilometre from Geita city (peri-urban). The inhabitants of Geita district are predominantly subsistence farmers and belong to the Sukuma and Zinza ethnic groups. Their main activities are farming, livestock keeping, small business, fishing, and mining. Malaria is highly endemic in this area with highest transmission occurring between March and June. Lake Zone has more than $80 \%$ prevalence of the $p f d h f r / p f d h p s$ quintuple mutant of IRNGE haplotype associated with SP resistance [22]. Pregnant women aged 15-49 years delivering at Geita district hospital or Katoro health centre were assessed for enrolment. Women were enrolled in our study if they fulfilled the following inclusion criteria: 1) singleton pregnancy; 2) seronegative for HIV; 3) absence of reported antimalarial treatment other than SP in the previous one month; and, 4) consented to be included in the study. Convenience sampling was used to recruit pregnant women who met the inclusion criteria and consented to participate in the study. Study participants were enrolled until the required sample size was reached.

\section{Sample size}

The two-proportion sample size formula without the correction factor by Fleiss [23] at 90\% power level and 5\% level of significance was used to estimate the required sample size. A minimum sample size of 426 women was calculated by considering the previous study that reported the proportion of women with placental malaria among $\geq$ three doses of SP group of $8 \%$ and that among < three doses of SP group of $17 \%$ [13]. A total of 431 delivering women in selected health facilities were recruited into the study.

\section{Data collection \\ Demographic and obstetric information}

Information was collected using an intervieweradministered structured questionnaire. The questionnaire collected socio-demographic information such as maternal age, marital status, education, and occupation. Also, obstetric history on parity, timing and frequency of ANC visits were collected. ANC cards were examined and information on the use of SP during pregnancy, number of doses taken, gestational age at first and subsequent SP doses, and the time lapse from the last dose to delivery were recorded. The ANC card also provided information on gestational age at first $\mathrm{ANC}$ clinic visit and frequency of ANC clinic attendance.

Birth weights of new-borns were measured within 24 hours of birth using SECA weighing scales (Vogel \& 
Halke Gmbh \& Co, Hamburg, Germany). Gestational age was estimated based on last normal menstrual period, and if uncertain and no early ultrasound scans available, the new Ballard score maturational assessment [24] was done within 24 hours of delivery by trained midwives.

\section{Blood sample collection, processing and examination of malaria parasites and antigens}

Malaria infection was screened in both placental and maternal peripheral blood samples by microscopy and rapid diagnostic tests (RDTs). Two $\mathrm{mL}$ of maternal peripheral venous blood were collected immediately after delivery, from which a thick blood smear was prepared and malaria RDT was done. Placental blood was collected using the procedures described elsewhere [25], for thick smear preparation. Both peripheral and placental blood samples were collected into the vacuum tubes containing ethylene diamine tetra acetic acid (EDTA) anticoagulants and smears were prepared within one hour after collection.

Maternal blood samples were evaluated by histidine rich protein II (HRP II) and parasite lactate dehydrogenase $(p \mathrm{LDH})$ antigen-based malaria RDTs (Standard Diagnostic Inc, South Korea). RDTs were performed according to the manufacturer's instructions and examined after $15 \mathrm{~min}$ following addition of four drops of the wash buffer.

Thick smears prepared from peripheral and placental blood samples were fixed with absolute ethanol and stained with 10\% Giemsa for $30 \mathrm{~min}$ [26]. Slides were examined by two independent laboratory technicians using light microscopy x 100 objectives under oil immersion for the presence of any malaria parasites stages. To minimize observation bias, the laboratory technicians reading the placental and peripheral smears were blinded to results of RDTs. Discordant results were given a third reading by a microbiologist blinded to the results of the first two readings, the result of which was considered final. A thick film was considered positive when any stage of malaria parasites were detected. At least 100 high power fields were examined before a thick smear was declared negative. Malaria parasites were counted against 500 leucocytes and parasite densities expressed per $\mu \mathrm{l}$ blood, assuming a white blood cell count of $8,000 / \mu l$ blood. The parasite density (parasite/ $\mu \mathrm{L}$ of blood) was then calculated as follows: Parasite density $=$ (number of parasites counted/ leukocytes counted) $\times$ white blood cell count $/ \mu \mathrm{L}$ blood [27]

\section{Definitions}

IPTp-SP was defined as provision of treatment doses of SP to asymptomatic pregnant women living in malariaendemic regions, regardless of malaria parasitaemia status. In areas of stable malaria transmission, WHO currently recommends IPTp-SP for all pregnant women at each scheduled ANC visit provided that each dose is taken four weeks apart from the other and continuing up to the time of delivery. Paucigravidae was defined as women in their first and second pregnancies and multigravidae referred to women with three or more pregnancies. Placental malaria was defined as direct detection of asexual stage of malaria parasites in placental thick smears regardless of Plasmodium species. Birth weights below 2,500 g measured within 24 hours of birth was regarded as LBW. Pre-term delivery was defined as delivery of an infant before 37 weeks gestational age.

\section{Data analysis}

Data collected were double-entered and cleaned using Epi-Data version 3.1 (CDC, Atlanta, GA, USA), and then exported to STATA version 12.0 (Stata Corp, College Station, TX, USA) for analysis. The primary exposure variable of interest was IPTp-SP usage, categorized into $<$ three doses versus $\geq$ three doses of IPTp. Data were summarized in the form of proportions and frequency tables for categorical variables. Means with their respective standard deviations were used to summarize continuous variables.

Bivariate logistic regression analyses were performed to determine the presence or absence of association between SP usage and placental malaria. All explanatory variables with $p<0.20$ in the bivariate analysis, were included in the multivariable analysis to further examine the association between IPTp-SP use and placental malaria. Secondary analyses were done to determine association between placental malaria and birth outcomes (birth weight and preterm delivery) using logistic and linear regression analyses. Adjusted odds ratio (AOR), regression coefficients and 95\% confidence intervals were reported. The level of significance was considered at $5 \%$.

\section{Ethical considerations}

Written informed consent for study participation was obtained from all participants aged 18 years and above. For women aged below 18 years, informed assent was obtained and their husbands, mothers or mother inlaws provided informed consents. The study was approved by the Joint Catholic University of Health and Allied Sciences (CUHAS)/Bugando Medical Centre (BMC) Research Ethical Committee (Certificate No. CREC/016/ 2014) and local authorities. Women found to have malaria at delivery were treated with the anti-malarial treatment protocol in line with national guidelines.

\section{Results}

\section{Study participant characteristics}

A total of 431 women were enrolled out of 1,701 total deliveries in Geita district hospital and Katoro rural health centre from May-June 2014. The demographic characteristics of the 431 women with singleton deliveries who participated in the present study are shown 
in Table 1. The participants were aged between 15-45 years, and the majority (77.49\%) were aged above 20 years. Nearly two-thirds (61.48\%) of the women delivered at Geita district hospital. Of 431 delivering women, onethird had previously visited at least four or more antenatal care visits. Of all the study participants, 227 (52.67\%) were in their first and second pregnancies. Majority (82.83\%) of women were married, $85.53 \%$ had primary level or no formal education and $85.85 \%$ were peasants and/or keeping livestock.

\section{Uptake of IPTp-SP}

Of 431 women delivering at selected health facilities, 26 (6.03\%) received three or more doses of SP, 104 (24.13\%) received two doses, $134(31.09 \%)$ received one dose and 167 (38.74\%) received no SP at all. Of 265 women who delivered at Geita hospital, 38 (14.34\%) did not receive any dose of SP, 109 (41.13\%) received one dose, 94 (35.47\%) received two doses and only 24 (9.06\%) took three or more doses of SP during pregnancy. Among 166 delivering women at Katoro health centre, 129 (77.71\%) did not receive any dose, $25(15.06 \%)$ received one dose,

\begin{tabular}{|c|c|}
\hline Variable & No (\%) \\
\hline \multicolumn{2}{|c|}{ Maternal age (years) } \\
\hline$<20$ & $97(22.51)$ \\
\hline$\geq 20$ & 334 (77.49) \\
\hline
\end{tabular}

Marital status

Single

74 (17.17)

Married

$357(82.83)$

Health facility

Geita Hospital

$265(61.48)$

Katoro HC

$166(38.52)$

Gravidity

Paucigravidae (G1/G2)

227 (52.67)

Multigravidae (G3+)

$204(47.33)$

Level of education

None/Primary

$360(83.53)$

Secondary/College

$71(16.47)$

Occupation

Peasants/livestock keeping

370 (85.85)

Employed/business

$61(14.15)$

ANC visits

$<4$ visits

276 (64.04)

$\geq 4$ visits

155 (35.96)

$\mathrm{ANC}=$ antenatal care, $\mathrm{SP}=$ sulphadoxine-pyrimethamine, $\mathrm{G} 1=$ primigravidae, $\mathrm{G} 2$ = secundigravidae, $\mathrm{G} 3+=$ gravida 3 and above, $\mathrm{HC}=$ health centre,

IPTp-SP = intermittent preventive treatment of malaria during pregnancy with SP.
$10(6.02 \%)$ received two doses and only $2(1.2 \%)$ received the recommended three or more doses of IPTp-SP. On bivariate logistic regression analysis (Table 2), the uptake of $\geq 3$ doses of SP during pregnancy was significantly associated with $\geq$ four ANC visits attended by the women $(\mathrm{OR}=4.41,95 \% \mathrm{CI}, 1.87-10.42, p=0.001)$, higher level of education $(\mathrm{OR}=4.22$, 95\% CI, 1.85-9.62, $p=0.001)$, area of residence in urban setting, $(\mathrm{OR}=8.20,95 \% \mathrm{CI}, 1.90$ $34.48, p=0.005)$, and being employed or doing business $(\mathrm{OR}=4.35,95 \% \mathrm{CI}, 1.85-10.10, p=0.001)$. There was no significant difference in the uptake of SP during pregnancy between age groups, marital status and gravidity. In multivariable analysis (Table 2), women delivering at Geita hospital $(\mathrm{AOR}=8.33, p=0.007)$ and attendance of four or more ANC visits $(\mathrm{AOR}=4.35, p=0.001)$ were associated with uptake of $\geq 3$ doses of IPTp-SP.

\section{Prevalence of malaria in pregnancy and birth outcomes}

The overall prevalence of malaria in pregnancy based on malaria RDT was $19.49 \%$ (95\% CI, 15.73-23.24), all of which occurred among women who received $<$ three doses of SP. The prevalence of malaria in pregnancy by RDT among delivering women at Geita hospital and Katoro health centre was $13.58 \%$ and $28.92 \%$ respectively. The sensitivity of RDT in detection of specific parasite proteins was very low. Over half, 60.94\% and $66.05 \%$ of women with peripheral and placental positive smears respectively had negative blood by RDT. Malaria Plasmodium species based on RDT were P. falciparum, 61.90\% ( $\mathrm{n}=52$ ), non-falciparum malaria parasites, $5.95 \%$ $(\mathrm{n}=5)$ and mixed infections, 32.14\% $(\mathrm{n}=27)$.

The overall prevalence of peripheral malaria by microscopy was $29.70 \%$ (95\% CI, 25.37-34.03). The prevalence of peripheral malaria by smear among delivering women at Geita hospital and Katoro health centre was $25.28 \%$ and $36.75 \%$ respectively. The overall geometric mean parasite density (GMPD) of peripheral parasitaemia was 167.75 (95\% CI, 141.52-198.85) parasites/ $\mu \mathrm{L}$. Of 128 delivering women with peripheral parasitaemia, 73 (57.03\%) had parasite density $<100$ parasites $/ \mu \mathrm{L}$.

The overall prevalence of placental malaria by microscopy was $37.60 \%$ (95\% CI, 33.00-42.18). The prevalence of placental malaria by microscopy among delivering women at Geita hospital and Katoro health centre was 35.09\% and $41.57 \%$ respectively. The overall GMPD (95\% CI) of the placenta was $144.31(126.25-164.95)$ parasites $/ \mu \mathrm{L}$. Among 162 delivering women with placental parasitaemia, $98(60.49 \%)$ had parasite density $<100$ parasites/ $\mu \mathrm{L}$.

Of 431 delivering women at selected health facilities, 58 (13.46\%) had pre-term deliveries. Of these, 54 (93.10\%) had gestational age 34-36 weeks at delivery. The prevalence of pre-term delivery among women delivering at Geita hospital and Katoro health centre was 9.43\% $(\mathrm{n}=25)$ and $19.88 \%(\mathrm{n}=33)$ respectively. Of 431 women 
Table 2 Factors associated with uptake of three or more doses of IPTp-SP among delivering women

\begin{tabular}{|c|c|c|c|c|c|c|}
\hline \multirow[t]{2}{*}{ Variable } & \multicolumn{2}{|c|}{ IPTp-SP uptake } & \multirow[t]{2}{*}{ COR $(95 \% \mathrm{Cl})$} & \multirow[t]{2}{*}{ P-value } & \multirow[t]{2}{*}{ AOR $(95 \% \mathrm{Cl})$} & \multirow[t]{2}{*}{ P-value } \\
\hline & $\mathrm{N}$ & $\geq 3$ doses, $\mathrm{n}(\%)$ & & & & \\
\hline \multicolumn{7}{|l|}{ Maternal age } \\
\hline$<20$ years & 97 & $3(3.09)$ & Reference & & Reference & \\
\hline$\geq 20$ years & 334 & $23(6.89)$ & $2.33(0.68-7.87)$ & 0.179 & $2.33(0.63-9.09)$ & 0.203 \\
\hline \multicolumn{7}{|l|}{ Marital status } \\
\hline Single & 74 & $7(9.49)$ & $1.86(0.75-4.60)$ & 0.180 & $2.37(0.84-6.67)$ & 0.103 \\
\hline Married & 357 & $19(5.32)$ & Reference & & Reference & \\
\hline \multicolumn{7}{|l|}{ Health facility } \\
\hline Katoro HC & 166 & $2(1.20)$ & Reference & & Reference & \\
\hline Geita hospital & 265 & $24(9.06)$ & $8.20(1.90-34.48)$ & 0.005 & 8.33 (1.79-33.33) & 0.007 \\
\hline \multicolumn{7}{|l|}{ Level of education } \\
\hline None/Primary & 360 & $15(4.17)$ & Reference & & Reference & \\
\hline Secondary/Higher & 71 & $11(15.49)$ & $4.22(1.85-9.62)$ & 0.001 & $1.69(0.66-4.35)$ & 0.275 \\
\hline \multicolumn{7}{|l|}{ Occupation } \\
\hline Peasants & 370 & $16(4.32)$ & Reference & & Reference & \\
\hline Employed/business & 61 & $10(16.39)$ & $4.35(1.85-10.10)$ & 0.001 & $1.85(0.70-5.00)$ & 0.214 \\
\hline \multicolumn{7}{|l|}{ ANC visits } \\
\hline$<4$ visits & 276 & $8(2.90)$ & Reference & & Reference & \\
\hline$\geq 4$ visits & 155 & $18(11.61)$ & $4.41(1.87-10.42)$ & 0.001 & $4.35(1.79-11.11)$ & 0.001 \\
\hline
\end{tabular}

ANC: antenatal care; AOR: adjusted odds ratio; COR: crude odds ratio; IPTp-SP: intermittent preventive treatment of malaria in pregnancy with sulphadoxinepyrimethamine; Significant $p$-values are presented in bold.

who delivered at selected health facilities, only $10(2.32 \%)$ had low birth weight babies. Of 10 infants with LBW, 8 (80\%) were born prematurely. The prevalence of LBW among delivering women at Geita hospital and Katoro health centre was 2.64\% $(\mathrm{n}=7)$ and $1.81 \%(\mathrm{n}=3)$ respectively.

\section{Factors influencing the placental parasite density}

On bivariate analysis, young women $<20$ years $(p=0.049)$, delivering at Katoro rural health centre $(p<0.001)$, having low level of education $(p=0.014)$ and being a peasant or keeping livestock $(p=0.034)$ had high placental parasite density. However, after adjusting for other covariates, women delivering at Katoro rural health centre $(p<0.001)$ and non-use of any type of bed net $(p=0.030)$ remained independently associated with placental parasite density. Receiving less than three doses of IPTp-SP was a perfect predictor of $>100$ parasites $/ \mu$ l of placental samples (Table 3).

\section{Factors influencing the prevalence of malaria in} pregnancy using RDT

Factors associated with prevalence of malaria in pregnancy by RDT are summarized in Table 4. Bivariate logistic regression analysis revealed that receipt of three or more doses of IPTp-SP was associated with negative
RDT. Maternal age younger than 20 years $(\mathrm{OR}=1.87$, $p=0.020)$, women from peri-urban area $(\mathrm{OR}=2.59$, $p<0.001$ ), paucigravidae ( $\mathrm{OR}=2.06, p=0.005)$, women with low level of education $(\mathrm{OR}=4.79, p=0.003)$, peasants $(\mathrm{OR}=3.04, p=0.021)$ were associated with increased odds of malaria in pregnancy using RDT in crude analysis. In multivariable analysis while controlling for possible confounders, women delivering at Katoro rural health centre $(\mathrm{AOR}=2.86, p<0.001)$ and those with low level of education (AOR $=3.51, p=0.023$ ) remained significantly associated with malaria in pregnancy based on RDT.

\section{Uptake of IPTp-SP and peripheral malaria by microscopy at delivery}

The association between IPTp-SP use and peripheral malaria by microscopy adjusted by other covariates is summarized in Table 5 . Having employment or being a business woman, secondary or higher level of education attainment, receipt of three or more doses of IPTp-SP, attendance of four or more ANC visits and bed net use were associated with decreased trend towards odds of peripheral malaria in bivariate analysis, although these variables did not reach statistical significance. Only women delivering at Katoro rural health centre had a significant trend towards increased odds of peripheral malaria by 
Table 3 Analysis of factors associated with placental parasite density among delivering women

\begin{tabular}{|c|c|c|c|c|c|c|}
\hline \multirow[t]{2}{*}{ Variable } & \multicolumn{2}{|c|}{ Parasite density } & \multirow{2}{*}{$\begin{array}{l}\text { Crude OR } \\
(95 \% \mathrm{Cl})\end{array}$} & \multirow[t]{2}{*}{ P-value } & \multirow{2}{*}{$\begin{array}{l}\text { Adjusted OR } \\
(95 \% \mathrm{Cl})\end{array}$} & \multirow[t]{2}{*}{ P-value } \\
\hline & $\mathrm{N}$ & No. of PD $>100 / \mu \mathrm{l},(\%)$ & & & & \\
\hline \multicolumn{7}{|l|}{ Maternal age } \\
\hline$<20$ years & 42 & $22(52.38)$ & $2.04(1.00,4.16)$ & 0.049 & $1.98(0.76,5.17)$ & 0.162 \\
\hline$\geq 20$ years & 120 & $42(35.00)$ & Reference & & Reference & \\
\hline \multicolumn{7}{|l|}{ Health facility } \\
\hline Geita hospital & 93 & $23(24.73)$ & Reference & & Reference & \\
\hline Katoro HC & 69 & $41(59.42)$ & $4.46(2.27,8.73)$ & $<0.001$ & $5.32(2.45,11.57)$ & $<0.001$ \\
\hline \multicolumn{7}{|l|}{ Gravidity } \\
\hline Paucigravidae & 94 & $43(45.74)$ & $1.89(0.98,3.63)$ & 0.058 & $2.05(0.85,4.93)$ & 0.110 \\
\hline Multigravidae & 68 & $21(30.88)$ & Reference & & Reference & \\
\hline \multicolumn{7}{|l|}{ Level of education } \\
\hline None/Primary & 140 & $61(43.57)$ & $4.89(1.38,17.29)$ & 0.014 & $3.18(0.80,12.55)$ & 0.099 \\
\hline Secondary/Higher & 22 & $3(13.64)$ & Reference & & Reference & \\
\hline \multicolumn{7}{|l|}{ Occupation } \\
\hline Peasant/livestock & 143 & $61(42.66)$ & $3.97(1.11,14.23)$ & 0.034 & $2.16(0.53,8.82)$ & 0.285 \\
\hline Employed/Business & 19 & $3(15.79)$ & Reference & & Reference & \\
\hline \multicolumn{7}{|l|}{ Bed net use } \\
\hline No & 6 & $5(88.33)$ & $8.33(0.95,73.13)$ & 0.056 & $12.88(1.27,130.15)$ & 0.030 \\
\hline Yes & 152 & $57(37.50)$ & Reference & & Reference & \\
\hline \multicolumn{7}{|l|}{ SP receipt } \\
\hline$<3$ doses & 158 & $64(40.51)$ & - & - & - & - \\
\hline$\geq 3$ doses & 4 & $0(0.00)$ & & & & \\
\hline
\end{tabular}

microscopy in both bivariate $(\mathrm{OR}=1.72, p=0.012)$ and multivariable analysis $(\mathrm{AOR}=2.77, p=0.014)$.

\section{Uptake of IPTp-SP and placental parasitaemia by microscopy}

As shown in Figure 1, the prevalence of placental malaria was lowest $(15.38 \%)$ among women who received three or more IPTp-SP doses and was highest (43.1\%) among those who did not receive any dose of SP. Placental malaria parasitaemia was higher among women aged below 20 years $(p$ $=0.188)$ and among paucigravidae $(p=0.084)$ in bivariate analysis although the difference was not statistically significant. In multivariable analysis (Table 6), adjusted for age, health facility, gravidity, bed net use and ethnicity; women who took three or more doses of IPTp-SP had a lower odds of placental parasitaemia when compared with those who took less than doses $(\mathrm{AOR}=0.31, p=0.039)$.

The influence of placental malaria parasitaemia and other covariates on pre-term delivery

Factors associated with pre-term delivery are shown in Table 7. In bivariate analysis, the odds of delivering a pre-term infant was higher among: 1) young women
( $p=0.008) ; 2)$ delivering at Katoro rural health centre $(p=0.002)$; 3) women with positive placental smear compared to uninfected $(p=0.001)$ and taking the last dose of IPTp-SP more than four weeks before delivery ( $p=0.069$ ). In multivariable analysis, being of young age $<20$ years $(p=0.029)$, having placental malaria $(p=0.002)$, and taking the last dose of SP more than four weeks before delivery $(p=0.026)$ remained significantly associated with increased odds of pre-term delivery.

\section{The influence of placental malaria parasitaemia and other} covariates on infant birth weights

The association between placental malaria and infant birth weight is summarized in Table 8. Mean birth weights were significantly lower: in infants born by mothers younger than 20 years $(2930 \pm 414 \mathrm{~g})$ compared to mothers aged 20 years or older (3271 $\pm 436 \mathrm{~g})$ ( $p<0.001)$, by paucigravidae (3141 $\pm 460 \mathrm{~g})$ compared to multigravida (3289 $\pm 436 \mathrm{~g}) \quad(p$ $<0.001)$, by women with less than four ANC visits (3141 \pm $460 \mathrm{~g})$ compared to four or more visits $(3289 \pm 428 \mathrm{~g})$, $(p=0.001)$, by women with placental parasitaemia (3096 \pm $448 \mathrm{~g})$ than that of uninfected counterparts $(3254 \pm 448 \mathrm{~g}$ ) ( $p$ <.001), and preterm birth $(2728 \pm 503 \mathrm{~g})$ than 
Table 4 Analysis of factors associated with malaria in pregnancy by rapid diagnostic test among delivering women

\begin{tabular}{|c|c|c|c|c|c|c|}
\hline \multirow[t]{2}{*}{ Variable } & \multicolumn{2}{|c|}{ MIP by RDT } & \multirow{2}{*}{$\begin{array}{l}\text { Crude OR } \\
(95 \% \mathrm{Cl})\end{array}$} & \multirow[t]{2}{*}{ P-value } & \multirow{2}{*}{$\begin{array}{l}\text { Adjusted OR } \\
(95 \% \mathrm{Cl})\end{array}$} & \multirow[t]{2}{*}{ P-value } \\
\hline & $\mathrm{N}$ & No. RDT-positive (\%) & & & & \\
\hline \multicolumn{7}{|l|}{ Maternal age } \\
\hline$<20$ years & 97 & $27(27.84)$ & $1.87(1.11,3.18)$ & 0.020 & $1.05(0.54,2.05)$ & 0.888 \\
\hline$\geq 20$ years & 334 & $57(17.07)$ & Reference & & Reference & \\
\hline \multicolumn{7}{|l|}{ Health facility } \\
\hline Geita hospital & 265 & $36(13.58)$ & Reference & & Reference & \\
\hline Katoro HC & 166 & $48(28.92)$ & $2.59(1.59,4.21)$ & $<0.001$ & $2.86(1.69,4.86)$ & $<0.001$ \\
\hline \multicolumn{7}{|l|}{ Gravidity } \\
\hline Paucigravidae & 227 & $56(24.67)$ & $2.06(1.25,3.39)$ & 0.005 & $2.37(1.29,4.38)$ & 0.006 \\
\hline Multigravidae & 204 & $28(13.73)$ & Reference & & Reference & \\
\hline \multicolumn{7}{|l|}{ Level of education } \\
\hline None/Primary & 360 & $80(22.22)$ & $4.79(1.69,13.53)$ & 0.003 & $3.51(1.19,10.39)$ & 0.023 \\
\hline Secondary/Higher & 71 & $4(5.63)$ & Reference & & Reference & \\
\hline \multicolumn{7}{|l|}{ Occupation } \\
\hline Peasant/livestock & 370 & 79 (21.35) & $3.04(1.18,7.85)$ & 0.021 & $1.86(0.68,5.10)$ & 0.230 \\
\hline Employed/Business & 61 & $5(8.20)$ & Reference & & Reference & \\
\hline \multicolumn{7}{|l|}{ Bed net use } \\
\hline No & 10 & $4(40.00)$ & Reference & & Reference & \\
\hline Yes & 403 & $77(19.11)$ & $0.35(0.10,1.28)$ & 0.115 & $0.28(0.07,1.10)$ & 0.067 \\
\hline \multicolumn{7}{|l|}{ SP receipt } \\
\hline$<3$ doses & 405 & $84(20.74)$ & - & - & - & - \\
\hline$\geq 3$ doses & 26 & $0(0.00)$ & & & & \\
\hline
\end{tabular}

that of term delivery $(3267 \pm 400 \mathrm{~g}),(p<0.001)$. On multiple linear regression analysis (Table 8 ), maternal age younger than 20 years $(p<0.001)$, paucigravidae $(p=0.002)$, women with placental malaria $(p=0.039)$, preterm delivery $(p<$ $0.001)$ and ANC visits less than four $(p=0.001)$ remained statistically significantly associated with delivery of infants with lower mean birth weights. The mean birth weights of infants born by women who received three or more doses of IPTp-SP were higher $(3311 \pm 476 \mathrm{~g})$ than those who received less than three doses ( $3187 \pm 452 \mathrm{~g})$; although this variable did not reach statistical significance $(p=0.713)$.

\section{Discussion}

\section{Uptake of IPTp-SP}

In SSA, the effectiveness of IPTp-SP in prevention of malaria-related adverse pregnancy outcomes is well documented [13-15,21]. However, the coverage of recommended doses of IPTp-SP in SSA is still very low [16]. In the present study, the uptake of at least one and two doses of SP were consistent with national estimates from the 2011-12 Tanzania HIV/AIDS and Malaria Indicator Survey report of $60 \%$ and $32 \%$, respectively [18]. However, the uptake of at least two doses of SP observed in the present study was lower than $35 \%$ reported previously in the same study area [28], reflecting the inconsistency of drug supply at the time of survey in the given area. The uptake of the recommended three doses of IPTp-SP has never been evaluated in Tanzania. The uptake of at least three doses of IPTp-SP in the present study was very low. The uptake of IPTp-SP in the present study is far below the Roll Back Malaria (RBM) target for all pregnant women living in areas with stable transmission in SSA to receive IPTp-SP by the end of 2015 [29].

Receipt of $\geq$ three doses of IPTp-SP in the present study was higher among women making $\geq$ four ANC clinic visits compared to women making fewer visits and among women residing in rural areas. These findings are consistent with that of Exavery et al. conducted in six selected districts of Tanzania [28], in Ghana by Hommerich et al. [15], in rural Burkina Faso by Gies et al. [14], and in Mali by Hill et al. [30]. ANC attendance is the entry point for receiving IPTp-SP; the more visits the woman attends the higher the number of SP she will receive. The ANC attendance of at least four visits was 36\% 
Table 5 Analysis of factors associated with peripheral malaria by microscopy among delivering women

\begin{tabular}{|c|c|c|c|c|c|c|}
\hline \multirow[t]{2}{*}{ Variable } & \multicolumn{2}{|c|}{ Peripheral malaria } & \multirow{2}{*}{$\begin{array}{l}\text { Crude OR } \\
(95 \% \mathrm{Cl})\end{array}$} & \multirow[t]{2}{*}{ P-value } & \multirow{2}{*}{$\begin{array}{l}\text { Adjusted OR } \\
(95 \% \mathrm{Cl})\end{array}$} & \multirow[t]{2}{*}{ P-value } \\
\hline & $\mathrm{N}$ & No. peripheral malaria positive (\%) & & & & \\
\hline \multicolumn{7}{|l|}{ Maternal age } \\
\hline$<20$ years & 97 & $33(34.02)$ & $130(0.80,2.10)$ & 0.291 & $1.28(0.76,2.14)$ & 0.350 \\
\hline$\geq 20$ years & 334 & $95(28.44)$ & Reference & & Reference & \\
\hline \multicolumn{7}{|l|}{ Health facility } \\
\hline Geita hospital & 265 & $67(25.28)$ & Reference & & Reference & \\
\hline Katoro HC & 166 & $61(36.75)$ & $1.72(1.13,2.61)$ & 0.012 & $1.76(1.12,2.77)$ & 0.014 \\
\hline \multicolumn{7}{|l|}{ Level of education } \\
\hline None/Primary & 360 & $113(31.39)$ & $1.71(0.93,3.15)$ & 0.086 & $1.29(0.66,2.53)$ & 0.458 \\
\hline Secondary/Higher & 71 & $15(21.13)$ & Reference & & Reference & \\
\hline \multicolumn{7}{|l|}{ Occupation } \\
\hline Peasant/livestock & 370 & $116(31.35)$ & $1.86(0.96,3.64)$ & 0.068 & $1.43(0.69,2.98)$ & 0.340 \\
\hline Employed/business & 61 & $12(19.67)$ & Reference & & Reference & \\
\hline \multicolumn{7}{|l|}{ SP receipt } \\
\hline$<3$ doses & 405 & $124(30.62)$ & Reference & & Reference & \\
\hline$\geq 3$ doses & 26 & $4(15.38)$ & $0.41(0.14,1.22)$ & 0.110 & $0.68(0.22,2.14)$ & 0.489 \\
\hline \multicolumn{7}{|l|}{ ANC visits } \\
\hline $1-3$ & 276 & $88(31.88)$ & $1.35(0.87,2.09)$ & 0.186 & $1.32(0.83,2.12)$ & 0.243 \\
\hline$\geq 4$ & 155 & $40(25.81)$ & Reference & & Reference & \\
\hline \multicolumn{7}{|l|}{ Bed net use } \\
\hline No & 10 & $5(50.00)$ & Reference & & Reference & \\
\hline Yes & 403 & $118(29.28)$ & $0.41(0.12,1.45)$ & 0.169 & $0.39(0.12,1.39)$ & 0.164 \\
\hline
\end{tabular}

but the uptake of at least three doses of SP during pregnancy was only $6 \%$ in this study, suggesting missed opportunities when women attended clinics but were not given IPTp-SP. The high ANC attendance rate with low uptake of IPTp can be explained in part by periodic shortage of SP in the health facility, poor adherence by health providers to provision of IPTp-SP and women's negative attitudes towards the use the drug during pregnancy [30,31].

\section{Prevalence of placental malaria}

The prevalence of malaria infection using RDT, peripheral and placental smears was $19.49 \%, 29.70 \%$ and $37.60 \%$ respectively. The sensitivity of RDT over microscopy in diagnosis of malaria in pregnancy was very low $(<40 \%)$. The difference can be explained, in part, that the performance of RDT depends on the level parasitaemia and the tests are more sensitive when parasite densities $>100$ parasites $/ \mu \mathrm{L}$ [32]. In the present study, over half of women with asymptomatic parasitaemia had low parasite density $<100$ parasites $/ \mu \mathrm{L}$. The finding is similar to an observational study conducted in Nigeria whereby SD Bioline RDT sensitivity was reported to be $47 \%$ among asymptomatic children [33] but contrary to a report from Burkina Faso where RDT had sensitivity of $89 \%$ [34]. The prevalence of malaria in pregnancy by RDTs was consistent with a recent report from Zambia by Tan et al. where 19.77\% [35] Plasmodium falciparum infection was observed in $94.05 \%$ of delivering women as either mixed infection (32.14\%) or as a mono-infection (61.91\%). This is consistent with previous reports that falciparum malaria was the predominant infection observed among pregnant women $[3,9]$. The prevalence of placental malaria by thick film smear was high $(37.6 \%)$ in this study. This prevalence of placental malaria can be attributed, in part, to increased transmission intensity with elevated re-infection rates between the last dose of SP and delivery, low uptake of IPTp-SP and that the study was conducted during the end of rainy season where transmission is at its highest peak [14]. The prevalence of placental malaria by microscopy is similar to those reported in Cameroon (33.7\%) and Ghana (38.6\%) [36,37] but was higher than previously reported in Uganda (17.5\%) and among Cameroonian parturient women $(25.5 \%)$ [38,39]. However, the prevalence of placental malaria in this study is lower than that reported by Ezebialu et al. (63.3\%) and Aribodor et al. (64.4\%) in 


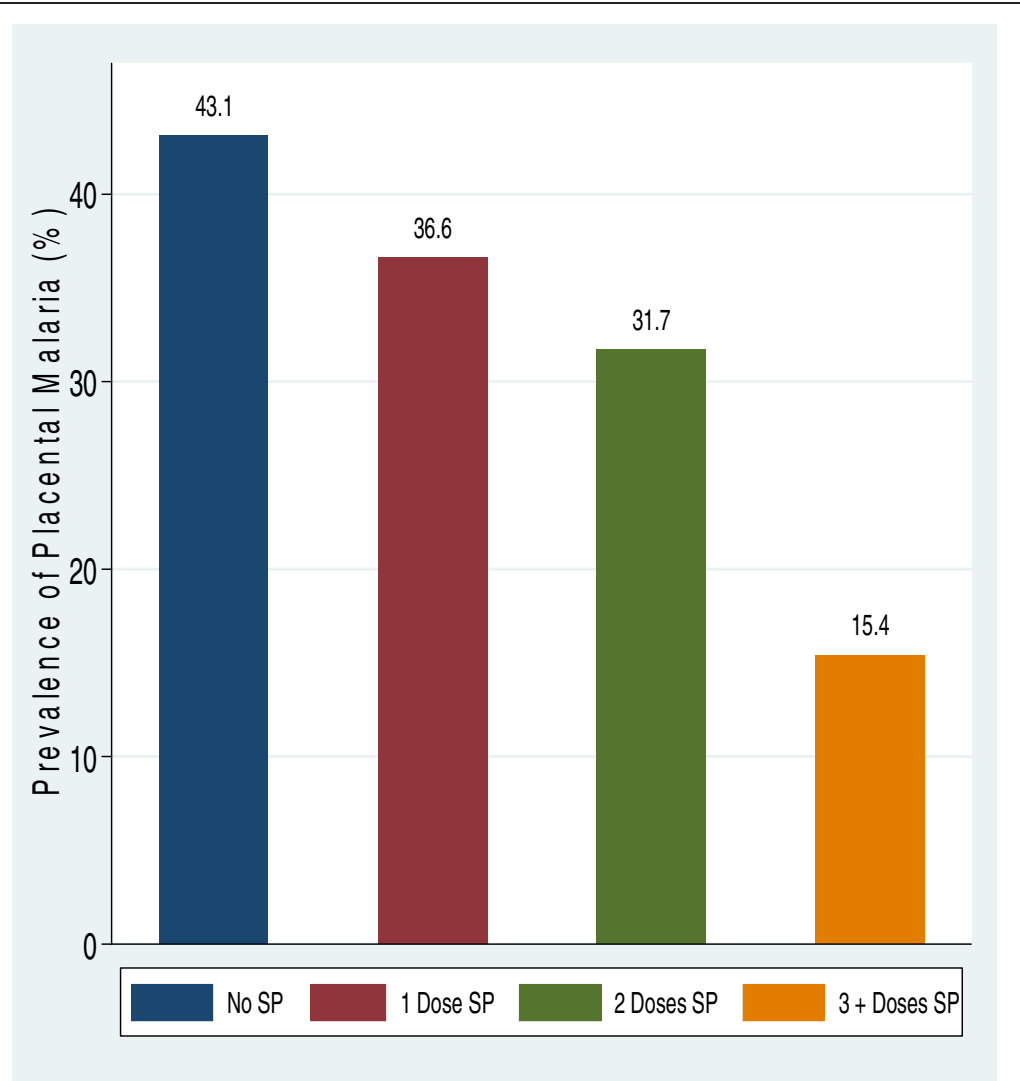

Figure 1 Prevalence of placental parasitaemia by frequency of sulphadoxine-pyrimethamine doses among 431 delivering women. The prevalence of placental parasitaemia was lowest among women who received three or more doses of SP during pregnancy and was highest among expectant women who did not receive any dose.

Nigeria respectively $[5,40]$.The differences in the prevalence of placental malaria across the regions can be explained by geographical variations in malaria transmission intensities, seasonality, differences in the characteristics of study participants, coverage of preventive measures, and study designs.

\section{IPTp-SP use and malaria in pregnancy}

In Geita district, uptake of three or more doses of IPTp-SP was a perfect predictor of negative malaria in pregnancy using RDT in bivariate analysis. Moreover, receipt of three or more doses of SP was associated with significantly reduction of placental parasitaemia, which supports the recent policy change from two to three or more doses of IPTp-SP in Tanzania. The superiority of three or more over less than three doses of SP in reduction of placental malaria and birth outcomes is consistent with a recent clinical trial conducted in Mali [13]. The significant protection of SP against placental malaria is not surprising in an area with moderate to high SP P. falciparum resistance [41].This supports the WHO recommendation to continue use of SP as IPTp even in areas with high levels of
SP resistance [42]. In north-eastern Tanzania where there is high SP resistance, Harrington et al. and Minja et al. reported loss of efficacy of SP as IPTp and exacerbation of adverse birth outcomes [43,44]. However, receipt of $\geq$ three doses of IPTp-SP was not associated with reduced odds of peripheral malaria in the present study. The lack of association could be explained, in part, by the fact that a small proportion of women took the recommended three or more doses of SP during pregnancy and that this may have reduced the power to produce an effect.

\section{Placental malaria and pre-term delivery}

The number of doses of IPTp-SP taken was not associated with reduced risk of pre-term delivery. However, women who received the last dose of IPTp-SP within four weeks of delivery had a $62 \%$ odds reduction of delivering pre-term infants. This is not surprising as the protection period of IPTp-SP is around four weeks.

The presence of placental parasitaemia was associated with a significant trend towards increased odds of preterm delivery. This finding concurs with those reported previously across SSA where malaria is highly endemic 
Table 6 Analysis of factors associated with placental malaria by microscopy among delivering women

\begin{tabular}{|c|c|c|c|c|c|c|}
\hline \multirow[t]{2}{*}{ Variable } & \multicolumn{2}{|c|}{ Placental malaria (PM) } & \multirow{2}{*}{$\begin{array}{l}\text { Crude OR } \\
(95 \% \mathrm{Cl})\end{array}$} & \multirow[t]{2}{*}{ P-value } & \multirow{2}{*}{$\begin{array}{l}\text { Adjusted OR } \\
(95 \% \mathrm{Cl})\end{array}$} & \multirow[t]{2}{*}{ P-value } \\
\hline & $\mathrm{N}$ & No. PM positive (\%) & & & & \\
\hline \multicolumn{7}{|l|}{ Maternal Age } \\
\hline$<20$ years & 97 & $42(43.30)$ & $1.36(0.86,2.16)$ & 0.188 & $1.08(0.62,1.89$ & 0.790 \\
\hline$\geq 20$ years & 334 & $120(35.93)$ & Reference & & Reference & \\
\hline \multicolumn{7}{|l|}{ Ethnicity } \\
\hline Sukuma/Zinza & 309 & $122(39.48)$ & $1.34(0.86,2.08)$ & 0.197 & $1.18(0.74,1.89)$ & 0.489 \\
\hline Other Tribes & 122 & $40(32.79$ & Reference & & Reference & \\
\hline \multicolumn{7}{|l|}{ Health facility } \\
\hline Geita hospital & 265 & $93(35.09)$ & Reference & & Reference & \\
\hline Katoro HC & 166 & $69(41.57)$ & $1.32(0.88,1.96)$ & 0.177 & $1.29(0.84,1.98)$ & 0.239 \\
\hline \multicolumn{7}{|l|}{ Gravidity } \\
\hline Paucigravidae & 227 & $94(41.41)$ & $1.41(0.95,2.09)$ & 0.084 & $1.43(0.89,2.30)$ & 0.135 \\
\hline Multigravidae & 204 & $68(33.33)$ & Reference & & Reference & \\
\hline \multicolumn{7}{|l|}{ SP receipt } \\
\hline$<3$ doses & 405 & $158(39.01)$ & Reference & & Reference & \\
\hline$\geq 3$ doses & 26 & $4(15.38)$ & $0.28(0.10,0.84)$ & 0.023 & $0.31(0.10,0.94)$ & 0.039 \\
\hline \multicolumn{7}{|l|}{ Bed net use } \\
\hline No & 10 & $6(60.00)$ & $2.48(0.69,8.92)$ & 0.165 & $2.53(0.69,9.26)$ & 0.159 \\
\hline Yes & 403 & $152(37.72)$ & Reference & & Reference & \\
\hline
\end{tabular}

$\mathrm{HC}=$ health centre; $\mathrm{OR}=$ odds ratio, $95 \% \mathrm{Cl}=95 \%$ confidence interval, $\mathrm{PM}=$ placental malaria; $\mathrm{SP}=$ sulphadoxine-pyrimethamine; Significant $\mathrm{p}$-values are presented in bold.

$[13,45]$. In contrast, in Cameroon, placental parasitaemia was not associated with pre-term delivery [46]. The pathophysiology of placental parasitaemia and pre-term delivery is uncertain. However, malaria-infected placentas often release inflammatory immune responses, such as antibodies, cytokines and macrophages, which may be responsible for early uterine stimulation initiating labour [3]. These mechanisms are thought to result in pre-term labour.

\section{Placental malaria and infant birth weight}

The prevalence of LBW in this study was very low (2.32\%) and the overall mean birth weight was high $(3194.20 \pm 2187 \mathrm{~g})$. The uptake of three or more doses of SP was not associated with a significant increase in mean birth weight of new-borns. The lack of association in this study could be explained, in part, by the low uptake of optimal doses of SP and high mean birth weight. In addition, the small sample size of the current study may not provide the power needed to detect the effect on birth weight.

Infants born to women who attended ANC clinics four or more times were on average $128 \mathrm{~g}$ heavier than infants of women who had attended ANC clinics less than three times. The association between ANC clinic visits and mean birth weight can be explained by the fact that more visits are associated with the receipt of more SP when readily available, and women supplemented with haematinics, counselled on nutrition during pregnancy, all of which are associated with improved birth weight. Moreover, infants born to young mothers and those born prematurely were $193 \mathrm{~g}$ and $128 \mathrm{~g}$ lighter than those born to older mothers and those born at term. Delivery of lower birth weight infants among young mothers can be explained by the fact that this age group is susceptible to malaria infection owing to inadequate pregnancy-associated immunity. For example, anticytoadherent antibodies that inhibit adhesion of P. falciparum to chondroitin sulphate A (CSA) is under-developed among first-time young pregnant women, compared to older non-first-time mothers with adequate immunity as a result of repeated exposure to malaria parasites [46]. Placental malaria was not associated with delivery of LBW owing to low prevalence of LBW in the current study that could not provide sufficient power to detect any potential associations. The low prevalence of LBW despite high prevalence of placental malaria can be explained by fact that there could be other causes of intrauterine foetal growth such as maternal malnutrition, maternal/foetal constitutional factors and other environmental non-infectious factors [47]. However, analysing birth weights as continuous variable, women with placental parasitaemia were more 
Table 7 Secondary analysis of factors associated with pre-term delivery among delivering women

\begin{tabular}{|c|c|c|c|c|c|c|}
\hline \multirow[t]{2}{*}{ Variable } & \multicolumn{2}{|c|}{ Pre-term delivery $^{\S}$} & \multirow{2}{*}{$\begin{array}{l}\text { Crude OR } \\
(95 \% \mathrm{Cl})\end{array}$} & \multirow[t]{2}{*}{ P-value } & \multirow{2}{*}{$\begin{array}{l}\text { Adjusted OR } \\
(95 \% \mathrm{Cl})\end{array}$} & \multirow[t]{2}{*}{ P-value } \\
\hline & $\mathrm{N}$ & No. PTD (\%) & & & & \\
\hline \multicolumn{7}{|l|}{ Maternal age } \\
\hline$<20$ years & 97 & $21(21.65)$ & $2.22(1.23,4.01)$ & 0.008 & $2.92(1.12,7.65)$ & 0.029 \\
\hline$\geq 20$ years & 334 & $37(11.08)$ & Reference & & Reference & \\
\hline \multicolumn{7}{|l|}{ Health facility } \\
\hline Geita hospital & 265 & $25(9.43)$ & Reference & & Reference & \\
\hline Katoro HC & 166 & $33(19.88)$ & $2.38(1.36,4.18)$ & 0.002 & $2.02(0.65,6.35)$ & 0.227 \\
\hline \multicolumn{7}{|l|}{ Peripheral malaria } \\
\hline Positive & 128 & $19(14.84)$ & $1.18(0.65,2.13)$ & 0.584 & $0.36(0.11,1.10)$ & 0.073 \\
\hline Negative & 303 & $39(12.87)$ & Reference & & Reference & \\
\hline \multicolumn{7}{|l|}{ Level of education } \\
\hline None/Primary & 360 & $53(14.72)$ & $2.28(0.88,5.92)$ & 0.091 & $1.69(0.45,6.33)$ & 0.439 \\
\hline Secondary/Higher & 71 & $5(7.04)$ & Reference & & Reference & \\
\hline \multicolumn{7}{|l|}{ Placental malaria } \\
\hline Positive & 162 & $33(20.37)$ & $2.50(1.42,4.38)$ & 0.001 & $4.67(1.74,12.58)$ & 0.002 \\
\hline Negative & 269 & $25(9.25)$ & Reference & & Reference & \\
\hline \multicolumn{7}{|l|}{ MIP by RDT } \\
\hline Positive & 84 & $16(19.05)$ & $1.71(0.91,3.22)$ & 0.097 & $2.13(0.69,6.59)$ & 0.188 \\
\hline Negative & 347 & $42(12.10)$ & Reference & & Reference & \\
\hline \multicolumn{7}{|l|}{ SP receipt } \\
\hline$<3$ doses & 405 & 55 (13.58) & Reference & & Reference & \\
\hline$\geq 3$ doses & 26 & $3(11.54)$ & $0.83(0.24,2.86)$ & 0.768 & $0.55(0.13,2.33)$ & 0.416 \\
\hline \multicolumn{7}{|l|}{ Last SP time lapse } \\
\hline$\leq 4$ weeks & 26 & $14(53.85)$ & $0.47(0.21,1.06)$ & 0.069 & $0.38(0.15,0.97)$ & 0.042 \\
\hline$>4$ weeks & 238 & $170(71.43)$ & Reference & & Reference & \\
\hline
\end{tabular}

$\mathrm{HC}=$ health centre; RDT = rapid diagnostic test, MIP = malaria in pregnancy, PTD = pre-term delivery, $\S=$ Assessed by first day of last menstrual period or by New Ballard Score; Significant $p$-values are presented in bold.

likely to deliver lower birth weight infants than uninfected women. The association between placental parasitaemia and low mean birth weight in this study is consistent with previous reports $[3,5,9,45,48]$. The delivery of LBW can be caused by pre-term delivery or by placental malaria sequestration causing intrauterine growth restriction (IUGR) $[9,48]$. Foetal growth restriction as a result of placental malaria sequestration is mediated by accumulation of infected erythrocytes into the maternal placental intervillous spaces that trigger chronic inflammatory responses leading to placental insufficiency $[2,48]$.

\section{Limitations}

This study was an analytical, cross-sectional study. Although efforts were made to control for confounders at the design and analyses stages, unidentified confounders may still have affected the observations. In addition, it is possible that not the entire dose of SP given to women was actually taken, as the receipt of SP was self-reported and some women did not consume SP as a directly observed therapy. There may have been a possibility of over-estimating IPTp-SP use in the study, as some participants may have tried to please the interviewer. A significant number of women who deliver outside health facilities in Tanzania may have had more adverse birth outcomes. However, this study had the limitation of recruiting study participants at delivery units. Therefore, this study was not representative of the wider population in north-western Tanzania. The lack of association between the uptake of $>$ three doses of IPTp-SP and birth outcomes (pre-term delivery and LBW) could be attributed to the small sample size and the proportion of women who took the recommended dose.

\section{Conclusions}

Placental parasitaemia is common in Geita district and is likely to be associated with pre-term delivery. Uptake of IPTp with SP is very low among pregnant women 
Table 8 Secondary analysis of factors associated with low birth weight delivery among delivering women

\begin{tabular}{|c|c|c|c|c|c|}
\hline Variable & $\begin{array}{l}\text { Mean birth } \\
\text { weight (SD) g }\end{array}$ & $\begin{array}{l}\text { Coefficient } \\
(95 \% \mathrm{Cl})\end{array}$ & P-value & $\begin{array}{l}\text { Coefficient } \\
(95 \% \mathrm{Cl})\end{array}$ & P-value \\
\hline \multicolumn{6}{|l|}{ Maternal age } \\
\hline$<20$ years & 2,930 (414) & $-341(-439,-243)$ & $<0.001$ & $-193(-297,-90)$ & $<0.001$ \\
\hline$\geq 20$ years & $3,271(436)$ & Reference & & Reference & \\
\hline \multicolumn{6}{|l|}{ Gravidity } \\
\hline Paucigravidae & $3,141(460)$ & $-243(-326,-160)$ & $<0.001$ & $-134(-220,-48)$ & 0.002 \\
\hline Multigravidae & $3,289(428)$ & Reference & & Reference & \\
\hline \multicolumn{6}{|l|}{ ANC visits } \\
\hline $1-3$ visits & $3,141(460)$ & $-148(-237,-60)$ & 0.001 & $-128(-206,-50)$ & 0.001 \\
\hline$\geq 4$ visits & $3,289(428)$ & Reference & & 1 & \\
\hline \multicolumn{6}{|l|}{ Placental malaria } \\
\hline Positive & $3,096(448)$ & $-158(-245,-70)$ & $<0.001$ & $-82(-160,-4)$ & 0.039 \\
\hline Negative & $3,254(448)$ & Reference & & 1 & \\
\hline \multicolumn{6}{|l|}{ SP receipt } \\
\hline$<3$ doses & $3,187(452)$ & $-125(-305,55)$ & 0.174 & $30(-129,188)$ & 0.713 \\
\hline$\geq 3$ doses & $3,311(476)$ & Reference & & Reference & \\
\hline \multicolumn{6}{|l|}{ Gestational age } \\
\hline Pre-term delivery & $2,728(503)$ & $-539(-654,-424)$ & $<0.001$ & $-479(-589,-369)$ & $<0.001$ \\
\hline Term delivery & $3,267(400)$ & Reference & & Reference & \\
\hline
\end{tabular}

$\mathrm{ANC}=$ antenatal care; $\mathrm{SD}=$ standard deviation, $95 \% \mathrm{Cl}=95 \%$ confidence interval, Significant $\mathrm{p}$-values are presented in bold .

attending ANC clinics in public health facilities of Geita district. However, the uptake of three or more doses of IPTp-SP in this area with highly intense malaria transmission is associated with reduction of placental malaria. Effort is needed to scale-up the uptake of optimal doses of IPTp-SP especially in peri-urban areas of Geita district. A longitudinal study may be required to evaluate the relationship between the uptake of recommended doses of IPTp-SP and birth outcomes in this area. Given substantial utilization of ANC in contrast to the low uptake of IPTp-SP in this population, qualitative research studies are needed to determine any underlying barriers of utilization of intermittent preventive treatment of malaria with SP during pregnancy.

\footnotetext{
Abbreviations

ANC: Antenatal care; AOR: Adjusted odds ratio; ARC: Adjusted Regression Coefficient; BMC: Bugando Medical Centre; Cl: Confidence interval; CSA: Chondroitin surface A; CUHAS: Catholic University Health of Allied Sciences; EDTA: Ethylene diamine tetra acetic acid; GMPD: Geometric mean parasite density; HIV: Human immunodeficiency virus; HRP II: Histidine-rich protein II; IPTp: Intermittent preventive treatment of malaria in pregnancy; IPTp-SP: Intermittent preventive treatment of malaria in pregnancy with sulphadoxine-pyrimethamine; IUGR: Intrauterine growth restriction; LBW: Low birth weight; RDT: Rapid diagnostic test; Pfdhfr: Plasmodium falciparum dihydrofolate reductase; Pfdhps: Plasmodium falciparum dihydropteroate synthase; pLDH: Parasite lactase dehydrogenase; RBM: Roll Back Malaria; SSA: Sub-Saharan Africa; SP: Sulphadoxine-pyrimethamine; WHO: World Health Organization.
}

Competing interests

The authors declare that they have no competing interests.

\section{Authors' contributions}

FJM: conception and design of study, data collection, analysis, interpretation and manuscript preparation. MM: data collection, analysis, interpretation and manuscript preparation. AD, DM, HDM, and SN: supervision and critically reading of manuscript for important and intellectual content. All authors read and approved the manuscript.

\section{Acknowledgements}

The authors thank all the pregnant women who volunteered to participate in this study, Geita district council and local health authorities, all midwives at delivery units of Geita district hospital and Katoro health centre for their valuable contributions to making the data available. We are very grateful to Mrs Editha Kazoya, Mr Pamphil Chokara and Mr Josephat J Kuboza for their technical assistance in preparation and examination of slides. HDM is supported by the Training Health Researchers into Vocational Excellence in East Africa (THRiVE) Programme funded by Wellcome Trust, grant number 087540 and by Tropical Disease Research, the Special Programme for Research and Training in Tropical Diseases, co-sponsored by UNICEF, UNDP, the World Bank and WHO", we acknowledge their support.

\section{Author details}

'School of Public Health, Catholic University of Health and Allied SciencesBugando, PO Box 1464, Mwanza, Tanzania. ${ }^{2}$ Department of Obstetrics and Gynaecology, Catholic University of Health and Allied Sciences- Bugando, PO Box 1464, Mwanza, Tanzania. ${ }^{3}$ School of Nursing and Midwifery, Mount Royal University, 4825 Mount Royal Gate SW, Calgary, AB T3E 6 K6, Canada. ${ }^{4}$ Department of Parasitology and Entomology, Catholic University of Health and Allied Sciences- Bugando, PO Box 1464, Mwanza, Tanzania.

Received: 11 September 2014 Accepted: 19 November 2014 Published: 24 November 2014 


\section{References}

1. Dellicour S, Tatem AJ, Guerra CA, Snow RW, ter Kuile FO: Quantifying the number of pregnancies at risk of malaria in 2007: a demographic study. PLoS Med 2010, 7:e1000221.

2. Desai M, ter Kuile FO, Nosten F, McGready R, Asamoa K, Brabin B, Newman RD: Epidemiology and burden of malaria in pregnancy. Lancet Infect Dis 2007, 7:93-104.

3. Guyatt HL, Snow RW: Impact of malaria during pregnancy on low birth weight in sub-Saharan Africa. Clin Microbiol Rev 2004, 17:760-769.

4. De Beaudrap P, Turyakira E, White L, Nabasumba C, Tumwebaze B, Muehlenbachs A, Guérin PJ, Boum Y, McGready R, Piola P: Impact of malaria during pregnancy on pregnancy outcomes in a Ugandan prospective cohort with intensive malaria screening and prompt treatment. Malar J 2013, 12:139.

5. Aribodor DN, Nwaorgu OC, Eneanya Cl, Okoli I, Etaga HO: Association of low birth weight and placental malarial infection in Nigeria. J Infect Dev Ctries 2009, 3:620-623.

6. Guyatt HL, Snow RW: The epidemiology and burden of Plasmodium falciparum -related anemia among pregnant women in sub-Saharan Africa. Am J Trop Med Hyg 2001, 64:36-44

7. Bardají A, Sigauque B, Sanz S, Maixenchs M, Ordi J, Aponte JJ, Mabunda S, Pedro L, Alonso PL, Menéndez C: Impact of malaria at the end of pregnancy on infant mortality and morbidity. J Infect Dis 2011 203:691-699.

8. Murphy SC, Breman JG: Gaps in the childhood malaria burden in Africa: cerebral malaria, neurological sequelae, anemia, respiratory distress, hypoglycemia, and complications of pregnancy. Am J Trop Med Hyg 2001, 64:57-67.

9. Steketee RW, Nahlen BL, Parise ME, Menendez C: The burden of malaria in pregnancy in malaria-endemic areas. Am J Trop Med Hyg 2001, 64:28-35.

10. President's Malaria Initiative: Tanzania Malaria Operational Plan FY 2014. http://www.pmi.gov/countries/mops/fy14/tanzania_mop_fy 14.pdf

11. Olsen BE, Hinderaker SG, Bergsjø P, Lie RT, Olsen OHE, Gasheka P, Gunnar K: Causes and characteristics of maternal deaths in rural northern Tanzania. Acta Obstet Gynecol Scand 2002, 81:1101-1109.

12. World Health Organization, Global Malaria Programme: Updated WHO policy recommendation: intermittent preventive treatment of malaria in pregnancy using sulfadoxine-pyrimethamine. Geneva: WHO; 2012. http://www.who.int/ malaria/iptp_sp_updated_policy_recommendation_en_102012.pdf.

13. Diakite OSM, Maiga OM, Kayentao K, Traoré BT, Djimde A, Traoré B, Diallo M, Traoré M, Ongoiba A, Doumbo S, Traoré MS, Dara A, Guindo O, Karim DM, Coulibaly S, Bougoudogo F, ter Kuile FO, Danis M, Doumbo OK: Superiority of 3 over 2 doses of intermittent preventive treatment with sulfadoxinepyrimethamine for the prevention of malaria during pregnancy in Mali: a randomized controlled trial. Clin Infect Dis 2011, 53:215-223.

14. Gies S, Coulibaly SO, Ouattara FT, D'Alessandro U: Individual efficacy of intermittent preventive treatment with sulfadoxine-pyrimethamine in primi- and secundigravidae in rural Burkina Faso: impact on parasitaemia, anaemia and birth weight. Trop Med Int Health 2009, 14:174-182.

15. Hommerich L, von Oertzen C, Bedu-Addo G, Holmberg V, Acquah PA, Eggelte TA, Bienzle U, Mockenhaupt FP: Decline of placental malaria in southern Ghana after the implementation of intermittent preventive treatment in pregnancy. Malar J 2007, 6:144.

16. van Eijk AM, Hill J, Alegana VA, Kirui V, Gething PW, ter Kuile FO, Snow RW: Coverage of malaria protection in pregnant women in sub-Saharan Africa: a synthesis and analysis of national survey data. Lancet Infect Dis 2011, 11:190-207.

17. WHO: World Malaria Report 2013. Geneva: World Health Organization; 2013. www.who.int/malaria/world_malaria_report_2013/en/index.html.

18. Tanzania HIV/AIDS and Malaria Indicator Survey 2011-12. Dar es Salaam, Tanzania: TACAIDS, ZAC, NBS, OCGS, and ICF International.

19. Minja DTR, Schmiegelow C, Mmbando B, Boström S, Oesterholt M, Magistrado P, Pehrson C, John D, Salanti A, Luty AJF, Lemnge M, Theander T, Lusingu JAM: Plasmodium falciparum mutant haplotype infection during pregnancy associated with reduced birth weight, Tanzania. Emerg Infect Dis 2013, 19:1446-1454.

20. Gesase S, Gosling RD, Hashim R, Ord R, Naidoo I, Mosha JF, Joho A, Mandia V, Mrema H, Mapunda E, Savael Z, Lemnge M, Mosha FW, Greenwood B, Roper C: High resistance of Plasmodium falciparum to sulphadoxine/ pyrimethamine in northern Tanzania and the emergence of dhps resistance mutation at codon. PLoS One 2009, 4:e4569.
21. Kayentao K, van Eijk AM, Naidoo I, Roper C, Mulokozi A, MacArtur JR, Luntamo M, Ashorn P, Doumbo OK, ter Kuile FO: Intermittent preventive therapy for malaria during pregnancy using 2 vs 3 or more doses of sulfadoxine-pyrimethamine and risk of low birth weight in Africa. Systemic review and Meta-analysis. JAMA 2013, 309:594-604.

22. Matondo SI, Temba GS, Kavishe AA, Kauki JS, Kalinga A, van Zwetselaar M, Reyburn H, Kavishe RA: High levels of sulphadoxine-pyrimethamine resistance Pfdhfr-Pfdhps quintuple mutations: a cross sectional survey of six regions in Tanzania. Malar J 2014, 13:152.

23. Fleiss JL, Levin B, Paik MC: Statistical Methods for Rates and Proportions, Volume 3rd. New York: John Wiley and Sons; 2003:64-72.

24. Ballard JL, Khoury JC, Wedig K, Wang L, Eilers-Walsman BLLR: New Ballard Score, expanded to include extremely premature infants. J Pediatr 1991, 119:417-423.

25. Mockenhaupt FP, Bedu-Addo G, von Gaertner C, Boyé R, Fricke K, Hannibal I, Karakaya F, Schaller M, Ulmen U, Acquah PA, Dietz E, Eggelte TA, Bienzle U: Detection and clinical manifestation of placental malaria in southern Ghana. Malar J 2006, 5:119.

26. Fried M, Muehlenbachs A, Duffy P: Diagnosing malaria in pregnancy : an update. Expert Rev Anti Infect Ther 2013, 10:1177-1187.

27. Cheesbrough M: Parasitological Tests in District Laboratory Practice in Tropical Countries Part 1. $2^{\text {nd }}$. New York: Cambridge University Press; 2005:239-258.

28. Exavery A, Mbaruku G, Mbuyita S, Makemba A, Kinyonge IP, Kweka H: Factors affecting uptake of optimal doses of sulphadoxine-pyrimethamine for intermittent preventive treatment of malaria in pregnancy in six districts of Tanzania. Malar J 2014, 13:22.

29. Roll Back Malaria Partnership: Refined/updated global malaria action plan objectives, targets, milestones and priorities beyond 2011. Geneva: Roll Back Malaria Partnership. http://www.rbm.who.int/gmap/gmap2011 update.pdf.

30. Hill J, Kayentao K, Toure M, Diarwara S, Bruce J, Smedley J, Doumbo OK, ter Kuile FO, Webster J: Effectiveness of antenatal clinics to deliver intermittent preventive treatment and insecticide treated nets for the control of malaria in pregnancy in Mali : a household survey. PLoS One 2014, 9:e92102.

31. Hill J, Hoyt J, van Eijk AM, D'Mello-Guyett L, ter Kuile FO, Steketee R, Smith $H$, Webster J: Factors affecting the delivery, access, and use of interventions to prevent malaria in pregnancy in sub-Saharan Africa: a systematic review and meta-analysis. PLoS Med 2013, 10:e1001488.

32. Moody A: Rapid diagnostic tests for malaria parasites. Clin Microbiol Rev 2002, 15:66-78.

33. Awortu JZ, Kufre UE, Igbida BF, Awortu TJ: Field evaluation of SD Bioline rapid malaria diagnostic test among asymptomatic malaria infected children in Port Harcourt, Nigeria. Res J Parasitol 2007, 2:39-44.

34. Singer LM, Newman RD, Diarra A, Moran AC, Huber CS, Stennies G, Sirima SB, Konate A, Yameogo M, Sawadogo R, Barnwell JW, Parise ME: Evaluation of a malaria rapid diagnostic test for assessing the burden of malaria during pregnancy. Am J Trop Med Hyg 2004, 70:481-485

35. Tan KR, Katalenich BL, Mace KE, Nambozi M, Taylor SM, Meshnick SR, Wiegand RE, Chalwe V, Filler SJ, Kamuliwo M, Craig AS: Efficacy of sulphadoxine-pyrimethamine for intermittent preventive treatment of malaria in Intermittent Preventive Treatment of malaria in Pregnancy, Mansa, Zambia. Malar J 2014, 13:227.

36. Wilson NO, Ceesay FK, Obed SA, Adjei AA, Gyasi RK, Rodney P, Ndjakani Y, Anderson WA, Lucchi NW, Stiles JK: Intermittent preventive treatment with sulfadoxine-pyrimethamine against malaria and anemia in pregnant women. Am J Trop Med Hyg 2011, 85:12-21.

37. Achidi EA, Kuoh AJ, Minang JT, Ngum B, Achimbom BM, Motaze SC, Ahmadou $\mathrm{MJ}$ : Malaria infection in pregnancy and its effects on hemoglobin levels in women from a malaria endemic area of Fako Division, South West Province, Cameroon. J Obstet Gynaecol 2005, 25:235-240.

38. Arinaitwe E, Ades V, Walakira A, Ninsiima B, Mugagga O, Patil TS, Schwartz A, Kamya MR, Nasr S, Chang M, Filler S, Dorsey G: Intermittent preventive therapy with sulfadoxine-pyrimethamine for malaria in pregnancy: a cross-sectional study from Tororo, Uganda. PLoS One 2013, 8:e73073.

39. Anchang-kimbi JK, Achidi EA, Nkegoum B, Sverremark-ekström E, Troyeblomberg M: Diagnostic comparison of malaria infection in peripheral blood, placental blood and placental biopsies in Cameroonian parturient women. Malar J 2009, 8:126.

40. Ezebialu IU, Eke AC, Ezeagwuna DA, Nwachukwu CE, Ifediata F, Ezebialu CU: Prevalence, pattern, and determinants of placental malaria in a population of southeastern Nigerian parturients. Int J Infect Dis 2012, 16:e860-e865. 
41. ter Kuile FO, van Eijk AM, Filler SJ: Effect of sulfadoxine-pyrimethamine resistance on the efficacy of intermittent preventive therapy for malaria control during pregnancy: a systematic review. JAMA 2007, 297:2603-2616.

42. WHO-MPAC: Malaria Policy Advisory Committee to the WHO: conclusions and recommendations of March 2013 meeting. Malar J 2013, 12:456.

43. Harrington WE, Mutabingwa TK, Kabyemela E, Fried M, Duffy PE: Intermittent treatment to prevent pregnancy malaria does not confer benefit in an area of widespread drug resistance. Clin Infect Dis 2011, 53:224-230.

44. Harrington WE, Morrison R, Fried M, Duffy PE: Intermittent preventive treatment in pregnant women is associated with increased risk of severe malaria in their offspring. PLoS One 2013, 8:e56183.

45. Newman RD, Hailemariam A, Jimma D, Degifie A, Kebede D, Rietveld AEC, Nahlen BL, Barnwell JW, Steketee RW, Parise ME: Burden of malaria during pregnancy in areas of stable and unstable transmission in Ethiopia during a nonepidemic year. J Infect Dis 2003, 187:1765-1772.

46. Tako EA, Zhou A, Lohoue J, Leke R, Taylor DW, Leke RFG: Risk factors for placental malaria and its effect on pregnancy outcome in Yaounde, Cameroon. Am J Trop Med Hyg 2005, 72:236-242.

47. Kramer MS: Determinants of low birth weight: methodological assessment and meta-analysis. Bull World Health Organ 1987, 65:663-737.

48. Menendez C, Ordi J, Ismail MR, Ventura PJ, Aponte JJ, Kahigwa E, Font F, Alonso PL: The impact of placental malaria on gestational age and birth weight. J Infect Dis 2000, 181:1740-1745.

doi:10.1186/1475-2875-13-455

Cite this article as: Mpogoro et al:: Uptake of intermittent preventive treatment with sulphadoxine-pyrimethamine for malaria during pregnancy and pregnancy outcomes: a cross-sectional study in Geita district,

North-Western Tanzania. Malaria Journal 2014 13:455.

\section{Submit your next manuscript to BioMed Central and take full advantage of:}

- Convenient online submission

- Thorough peer review

- No space constraints or color figure charges

- Immediate publication on acceptance

- Inclusion in PubMed, CAS, Scopus and Google Scholar

- Research which is freely available for redistribution 